\title{
Research on the Impact of Honeycomb Sandwich Plates at Natural Frequency Changed with Geometric Parameters
}

\author{
Xiaoman Liu ${ }^{1}$, Guojun $\mathrm{Du}^{1, *}$ and Xiaoxia $\mathrm{Niu}^{2}$ \\ ${ }^{1}$ College of Civil Engineering \& Mechanics, Yanshan University, Qinhuangdao, China \\ ${ }^{2}$ College of Information and Technology Engineering, Yanshan University, Qinhuangdao, China
}

\begin{abstract}
In this paper, in order to find the impact of sandwich plates at natural frequency changed with its geometric and physical parameters, we deduced free vibration equation derived sandwich panels. We took the hexagonal honeycomb sandwich plates as example, and derived natural frequencies for each for use in the modeling and modal analysis, and then discussed the effect of skin thickness, core spacing and core height on the natural frequency of honeycomb sandwich plates. The result shows that the honeycomb sandwich plates have great rigidity, and compared to other parameters, the change of core height has a greater impact on the natural frequencies of honeycomb sandwich plates. When the surface thickness of quadrilateral honeycomb sandwich plates becomes thicker, its natural frequency increases with increasing length of core grid. When sandwich mesh length reaches a certain level, the natural frequency increased firstly and then decreased. When the sandwich mesh length is longer enough, the frequency decreased with the increase in the length. When the core height increased, the natural frequency increased. When the quadrilateral mesh becomes longer, its natural frequency appears to decline after the initial increase. The influence of geometric parameters on hexagonal honeycomb sandwich plates is same as on quadrilateral honeycomb and other soft sandwich plates. Later experiments confirmed some of above conclusions.
\end{abstract}

Keywords: ANSYS, geometric and physical parameters, honeycomb sandwich plates, modal, natural frequency.

\section{INTRODUCTION}

Composite laminate structures for static, dynamic theoretical analysis and computing applications, as well as viscoelastic polymer material in sandwich plates and shell structures, use a special method in mechanics applications. By selecting the appropriate surface and laminated materials, good vibration, heat insulation, sound insulation etc. can be achieved; it has thus broad application prospects [1-3], especially in the automotive, aerospace, construction, shipbuilding and mechanical construction fields $[4,5]$, in which the automotive and construction are two of the most promising fields. In the automobile industry, the quality of transport to reduce the honeycomb structure is widely used in aircraft, aerospace and aerospace industries. The new results enable the structural analysis to be decoupled from an analysis of shock propagation in the air [6]. The study complements the prior work on the role of fluid-structure interaction in the design and assessment of sandwich plates subject to water shocks [7]. Square honeycomb and folded plate core topologies are considered. Fluid-structure interaction enhances the performance of sandwich plates relative to solid plates under intense air shocks, Ashkan Vaziri investigates two methods for applying the loading to the sandwich plate $[8,9]$, responses are contrasted for loads applied as a time-dependent pressure history versus imposition of an initial velocity.

*Address correspondence to this author at the College of Civil Engineering and Mechanics, Yanshan University, Qinhuangdao, China;

Tel: (86) 13833526329; Fax: (86)+03358057101;

E-mails: dugj2002@ysu.edu.cn,1xm2001@ysu.edu.cn

\section{INHERENT VIBRATION EQUATION OF HONEYCOMB SANDWICH PLATES}

When the honeycomb sandwich panels undergo natural vibration in the absence of external force, the amplitude of the displacement of the plane is much smaller than the horizontal deflection amplitude. Therefore, you can ignore the inertial force generated by the intermediate displacement, using sandwich plate theory, so the basic equation can be derived based on the relationship between shear, load and moment [10-12].

$$
\begin{aligned}
& \mathbf{M}_{x}=-D\left(\frac{\partial \varphi_{x}}{\partial x}+v_{f} \frac{\partial \varphi_{y}}{\partial y}\right)-2 D_{f}\left(\frac{\partial^{2} w}{\partial x^{2}}+v_{f} \frac{\partial^{2} w}{\partial y^{2}}\right) \\
& \mathbf{M}_{y}=-D\left(\frac{\partial \varphi_{y}}{\partial y}+v_{f} \frac{\partial \varphi_{x}}{\partial x}\right)-2 D_{f}\left(\frac{\partial^{2} w}{\partial y^{2}}+v_{f} \frac{\partial^{2} w}{\partial x^{2}}\right) \\
& \mathbf{M}_{x y}=-\frac{1}{2}\left(1-v_{f}\right) D\left(\frac{\partial \varphi_{x}}{\partial y}+\frac{\partial \varphi_{y}}{\partial x}\right)-2\left(1-v_{f}\right) D_{f} \frac{\partial^{2} w}{\partial x \partial y} \\
& Q_{x}=C\left(\frac{\partial w}{\partial x}-\varphi_{x}\right)-2 D_{f} \frac{\partial}{\partial x}\left(\frac{\partial^{2} w}{\partial x^{2}}+\frac{\partial^{2} w}{\partial y^{2}}\right) \\
& Q_{y}=C\left(\frac{\partial w}{\partial y}-\varphi_{y}\right)-2 D_{f} \frac{\partial}{\partial y}\left(\frac{\partial^{2} w}{\partial x^{2}}+\frac{\partial^{2} w}{\partial y^{2}}\right)
\end{aligned}
$$

By introducing the sandwich plate surface stress- strain relation equation, the equation of motion into the sandwich board, after several parameter substitutions, acquired a sandwich board free vibration equation. 
$\frac{D}{2}\left(1-v_{f}\right) \nabla^{2} f-C f=0$

$\left(D+2 D_{f}\right) \nabla^{4} \omega-\frac{2 D_{1} D_{2}}{C} \nabla^{6} \omega-\frac{1}{R} \frac{\partial^{2} \Phi}{\partial x^{2}}-\rho \bar{\omega}^{2}\left(\omega-\frac{D}{C} \nabla^{2} \omega\right)=0$

\section{HONEYCOMB SANDWICH PLATES MODELING PROCESS BASED ON ANSYS}

The side length of the hexagonal honeycomb sandwich panels is $0.6 \mathrm{~m} * 0.6 \mathrm{~m}$, thickness is $0.003 \mathrm{~m}$, sandwich mesh side length is $0.03 \mathrm{~m}$, sandwich thickness is $0.001 \mathrm{~m}$, and mezzanine height is $0.03 \mathrm{~m}$. Create a hexagon, then copy it to extend to form a hexagon, beneath the newly generated long hexagonal surface to identify the key points to form a new hexagonal, as shown in Fig. (1). In the newly generated copy, extended hexagons form a new lengthy hexagon surface.

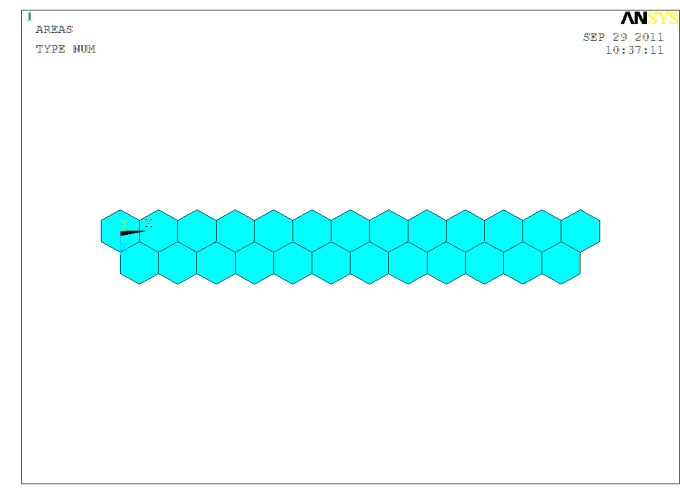

Fig. (1). Two-line hexagonal surface.

The new generation of multi-faceted hexagons replicate the formation of large multi-faceted hexagons, in the face of the origin of the four reference points that were selected $(0,0),(0,0.6),(0.6,0),(0.6,0.6)$ i.e. four points together into a straight line, and then face segmentation, Pick a point above the origin, the origin is connected to form a baseline, then along the newly formed straight surfaces stretch this entry generating body, followed by removing the body, that will then leave the surface, it will be the model hexagonal honeycomb sandwich panels shaping up as shown in Fig. (2).

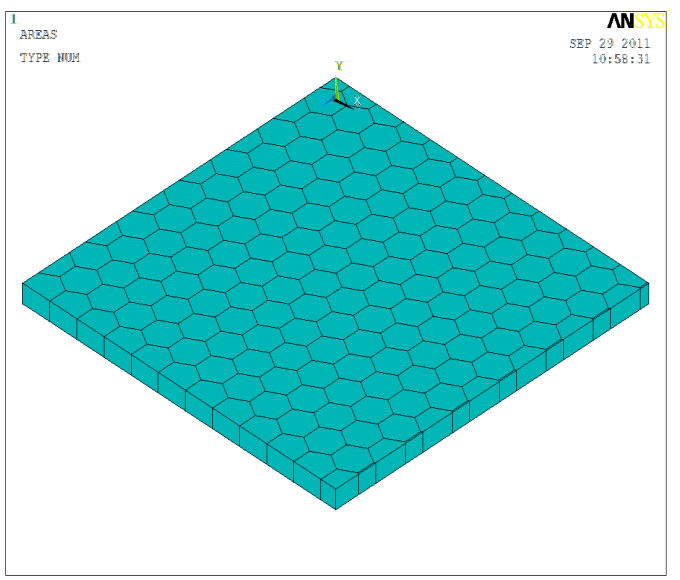

Fig. (2). Hexagon sandwich plates.

\section{THE NATURAL FREQUENCY OF HONEYCOMB SANDWICH PLATES CHANGED WITH GEOMETRIC AND PHYSICAL PARAMETERS}

In order to find the impact of sandwich plates at a natural frequency changed with its geometric and physical parameters, we deduced free vibration equation derived sandwich panels. The hexagonal honeycomb sandwich plates were taken as example, and natural frequencies were derived for each for use in modeling and modal analysis. Finally, the influence of skin thickness, core spacing and core height, on the natural frequency of honeycomb sandwich plates was discussed.

\subsection{Plate Thickness Variation Affects the Natural Frequency}

Hexagonal honeycomb sandwich panels studied under the free vibration, whose upper and lower plates are made of steel or aluminum. A modal analysis based on ANSYS software was conducted.

Examples: There is a $0.6 \mathrm{~m} \times 0.6 \mathrm{~m}$ hexagonal honey-comb sandwich plate, with sandwich height $0.03 \mathrm{~m}$, sandwich mesh sides $0.010 \mathrm{~m}, 0.015 \mathrm{~m}, 0.020 \mathrm{~m}, 0.025 \mathrm{~m}, 0.030 \mathrm{~m}, 0.035 \mathrm{~m}$, $0.040 \mathrm{~m}, 0.050 \mathrm{~m}, 0.060 \mathrm{~m}$ respectively. Each side of freedom, material parameters were: $E_{l}=200 \mathrm{GPa}, E_{2}=90 \mathrm{GPa}, v=0.3$, $\rho=7800 \mathrm{~kg} / \mathrm{m}^{3}$. Skin thickness is $0.002 \mathrm{~m}, 0.003 \mathrm{~m}, 0.004 \mathrm{~m}$, $0.005 \mathrm{~m}, 0.006 \mathrm{~m}$. These sandwich plates' first natural frequencies are given in Table 1.

When mesh side is $0.01 \mathrm{~m}$, natural frequency of the sandwich plate with a thickness of the upper and lower thick plate increased. The rate of increase becomes smaller, that is, the slope becomes smaller.

When mesh side is $0.035 \mathrm{~m}, 0.04 \mathrm{~m}, 0.05 \mathrm{~m}, 0.06 \mathrm{~m}$ respectively, natural frequency of the sandwich plate with the thickness of the upper and lower thicker plates decrease linearly.

\subsection{Sandwich Core Height Changed at Natural Frequency of Honeycomb Sandwich Plates}

From the above chart presenting curve data analysis in Fig. (3), it has been identified that on the hexagonal honeycomb sandwich panels at the high fixed core sandwich, with the change in the thickness of the upper and lower plates, natural frequency change occurs more regularly.

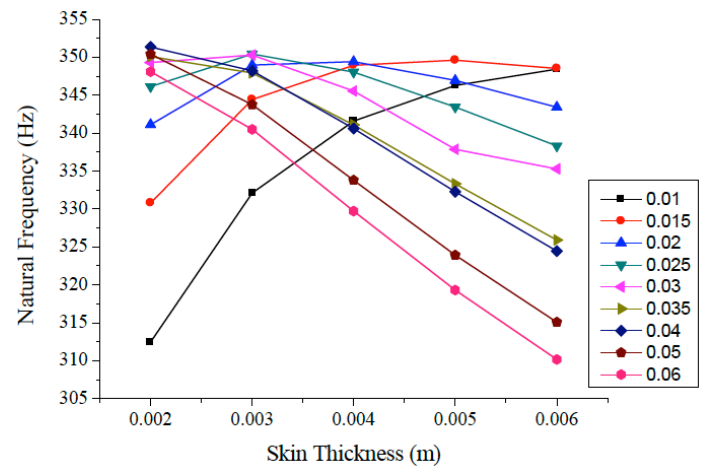

Fig. (3). Natural frequency changed with different skin thickness and mesh sides of hexagon sandwich plates. 
Table 1. Frequency at different skin thickness.

\begin{tabular}{|c|c|c|c|c|c|}
\hline \multirow{2}{*}{$\begin{array}{l}\text { Frequency }(\mathrm{Hz}) \\
\text { Mesh length (m) }\end{array}$} & \multicolumn{5}{|c|}{ Skin thickness (m) } \\
\hline & 0.002 & 0.003 & 0.004 & 0.005 & 0.006 \\
\hline 0.010 & 312.45 & 332.1 & 341.59 & 346.26 & 348.43 \\
\hline 0.015 & 330.79 & 344.42 & 348.95 & 349.62 & 348.52 \\
\hline 0.020 & 341.12 & 348.97 & 349.41 & 346.95 & 343.41 \\
\hline 0.025 & 346.14 & 350.42 & 348.03 & 343.45 & 338.30 \\
\hline 0.030 & 349.31 & 350.28 & 345.55 & 342.86 & 339.27 \\
\hline 0.035 & 350.09 & 347.92 & 341.07 & 333.32 & 325.89 \\
\hline 0.040 & 351.35 & 348.22 & 340.61 & 332.28 & 324.44 \\
\hline 0.050 & 350.40 & 343.76 & 333.80 & 323.92 & 315.06 \\
\hline 0.060 & 348.11 & 340.48 & 329.72 & 319.31 & 310.17 \\
\hline Mesh length (m) & 0.002 & 0.003 & 0.004 & 0.005 & 0.006 \\
\hline Frequency $(\mathrm{Hz})$ & \multicolumn{5}{|c|}{ Skin thickness (m) } \\
\hline
\end{tabular}

Table 2. The natural frequency at different sandwich core height.

\begin{tabular}{|c|c|c|c|c|c|}
\hline \multirow{2}{*}{$\begin{array}{l}\text { Frequency }(\mathrm{Hz}) \\
\text { Mesh length (m) }\end{array}$} & \multicolumn{5}{|c|}{ Sandwich core height (m) } \\
\hline & 0.02 & 0.03 & 0.04 & 0.05 & 0.06 \\
\hline 0.010 & 245 & 332 & 404 & 466 & 520 \\
\hline 0.015 & 252 & 340 & 415 & 478 & 543 \\
\hline 0.020 & 254 & 348 & 428 & 497 & 557 \\
\hline 0.025 & 255 & 350 & 431 & 500 & 561 \\
\hline 0.035 & 254 & 348 & 428 & 497 & 557 \\
\hline 0.040 & 242 & 348 & 427 & 496 & 557 \\
\hline 0.050 & 250 & 343 & 420 & 485 & 545 \\
\hline 0.060 & 250 & 340 & 416 & 479 & 539 \\
\hline
\end{tabular}

When mesh side is $0.015 \mathrm{~m}, 0.02 \mathrm{~m}, 0.025 \mathrm{~m}, 0.03 \mathrm{~m}$, natural frequency of the sandwich plate with the upper and lower plate thickness after thickening and initial increase, decreased based on ANSYS software.

Examples: There is a $0.6 \mathrm{~m} \times 0.6 \mathrm{~m}$ hexagonal honey-comb sandwich plate, with the thickness of the upper and lower plates to be $0.03 \mathrm{~m}$. Sandwich mesh sides were: $0.010 \mathrm{~m}$, $0.015 \mathrm{~m}, 0.020 \mathrm{~m}, 0.025 \mathrm{~m}, 0.030 \mathrm{~m}, 0.035 \mathrm{~m}, 0.040 \mathrm{~m}, 0.050 \mathrm{~m}$, $0.060 \mathrm{~m}$. Each side of freedom, material parameters were: $E_{l}=$ 200GPa, $E_{2}=90 \mathrm{GPa}, v=0.3, \rho=7800 \mathrm{~kg} / \mathrm{m}^{3}$; sandwich height were: $0.002 \mathrm{~m}, 0.003 \mathrm{~m}, 0.004 \mathrm{~m}, 0.005 \mathrm{~m}, 0.006 \mathrm{~m}$. These sandwich plates' first natural frequencies are given in Table $\mathbf{2}$.

Data from the Table 2 and Fig. (4). show that in a fixed timeframe and changes in the height, for hexagonal honeycomb sandwich panels with the upper and lower plates, sandwich plate's natural frequency also changes more regularly: With the increase in height of the sandwich core, hexagonal honeycomb sandwich panels natural frequency dramatically increases.

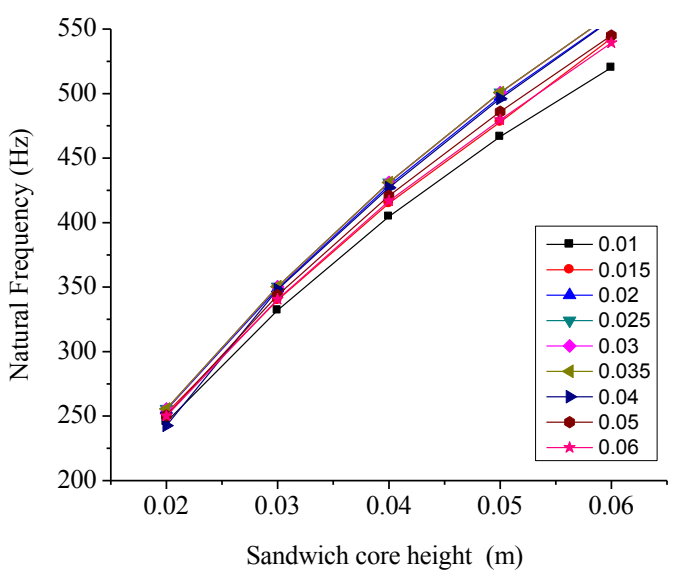

Fig. (4). Natural frequency with sandwich core height change and different mesh sides of hexagonal sandwich plates. 
When the sandwich core height is $0.02 \mathrm{~m}$ to $0.04 \mathrm{~m}$, the interlayer sheet's natural frequency increase is the greatest. When the sandwich core increased from $0.04 \mathrm{~m}$ to $0.05 \mathrm{~m}$, sandwich plate natural frequency increase becomes smaller.

When mesh side lengths are $0.035 \mathrm{~m}, 0.04 \mathrm{~m}, 0.05 \mathrm{~m}$ and $0.06 \mathrm{~m}$, showing the sandwich height variation, no significant difference is found between their natural frequency, until when the sandwich side length is $0.03 \mathrm{~m}$. But when the sandwich side lengths are $0.01 \mathrm{~m}, 0.015 \mathrm{~m}, 0.02 \mathrm{~m}, 0.025 \mathrm{~m}$, the side of the sandwich becomes large along with the natural frequency of the interlayer sheet, and as the sandwich core height increases, the gap between also increases.

\subsection{Sandwich Core Mesh Side Change at the Natural Frequency of Honeycomb Sandwich Plates}

Data from the above two tables shows that the change in sandwich core height on a hexagonal honeycomb sandwich panel plate could help calculate the variation in the firstorder natural frequency; we could draw a side length change on a hexagonal honeycomb sandwich plate.

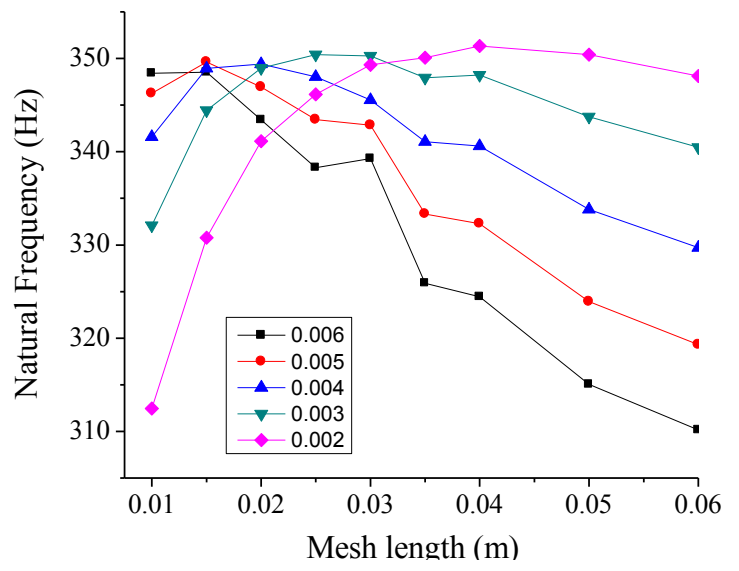

Fig. (5). Natural frequency with mesh length change and different skin thickness of hexagon sandwich plates.

Figs. (5 \& 6) show that on hexagonal honeycomb sandwich panels with the upper and lower plates having high fixed core length/thickness, side length changes with time and the natural frequency change occurs more regularly.

When the core height is fixed, hexagonal honeycomb sandwich panels having different thickness of upper and lower plate sides with a grid showing changes in its natural frequency shows decreasing trend after the first growth. And with the increase of the mesh side length, its inherent frequency reduction rate increases.

When the upper and lower plate thickness is fixed, different height hexagonal honeycomb core sandwich panels with mesh side, change its natural frequency initially and then show increasing or decreasing trend. However, the changes are not significant.

\section{SANDWICH PLATE MODAL TEST}

Modal shows the overall characteristics of the inherent elasticity of the structure. If you figure out the structure within a frequency range of each susceptible modal characteristic at the main stage by modal analysis method, it is possible to predict the actual vibrational response of the structure inherent in this band under the action of various external or internal vibration sources. Therefore, modal analysis is an important method for fault diagnosis, structural dynamic design and equipment analysis. Modal analysis provides a practical study of structural vibration in an effective way. Modal parameters can be achieved by calculation or experimental analysis, which is known as modal analysis. If this analysis is done by the finite element method to obtain modal parameters, then it is known as modal analysis calculation. After parameter identification, modal parameters are obtained through the system if the input and output signals of the test will be collected, this process is called experimental modal analysis.

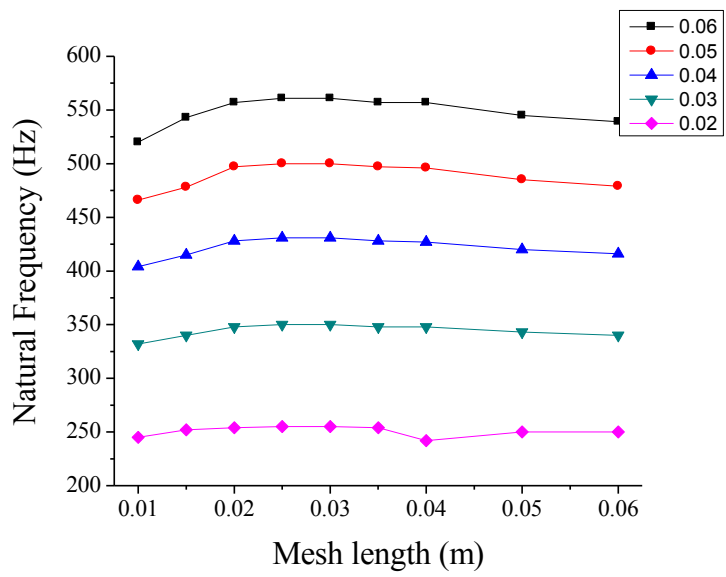

Fig. (6). Natural frequency with mesh length change and different core height of hexagon sandwich plates.

Testing Examples: There is a $0.3 \mathrm{~m} \times 0.2 \mathrm{~m}$ hexagonal honeycomb sandwich plate with upper and lower plates having thickness: $0.001 \mathrm{~m}$ and $0.002 \mathrm{~m}$ and $0.003 \mathrm{~m}$. Sandwich mesh side is $0.010 \mathrm{~m}$, and sandwich core height were $0.015 \mathrm{~m}, 0.020 \mathrm{~m}$ and $0.030 \mathrm{~m}$. Each side of freedom, material parameters were: $E_{1}=200 \mathrm{GPa}, E_{2}=90 \mathrm{GPa}, v=0.3$, $\rho_{1}=7800 \mathrm{~kg} / \mathrm{m}^{3}, \rho_{2}=2700 \mathrm{~kg} / \mathrm{m}^{3}$ and mesh side length is 6 $\mathrm{mm}$.

We adopted INV1601B vibration type tester and INV1601 DASP software in order to perform model analysis of sandwich plate. In the process of analysis, we tested sandwich plate by adopting the experimental methods that is the multipoint excitation and taking a single point under free constraint conditions. Its stationing way uses $4 \times 5$ units, a total of 30 points, table board and sandwich connected by gluing way. And freedom constraint condition uses 4 angle soft underlay like sponge etc., simulation, as shown in Figs. (7\&8).

As can be observed from Fig. (9), the stiffness of pic2 was higher than pic1, which coincides with result of the above study. We had recorded data in the Table 3 and then drew the curves as shown in Fig. (9). 

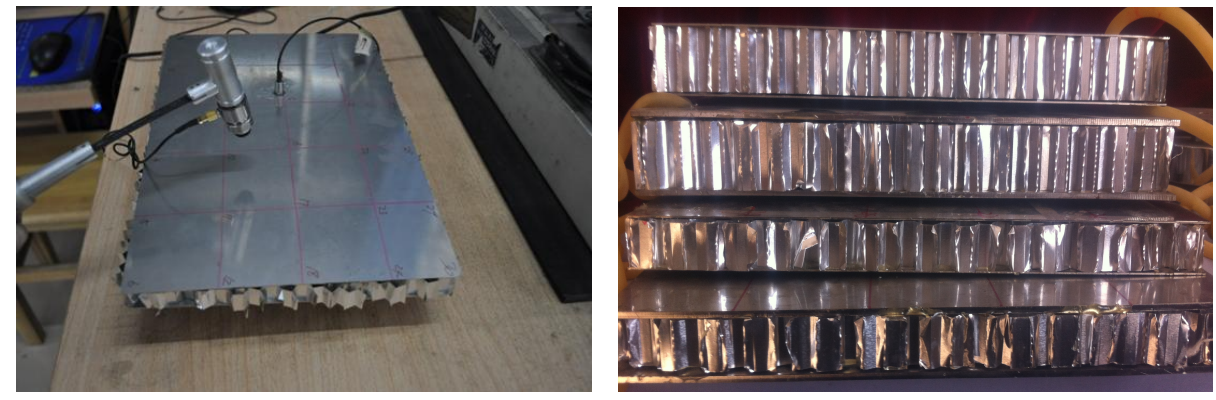

Fig. (7). Sandwich plate experiment.

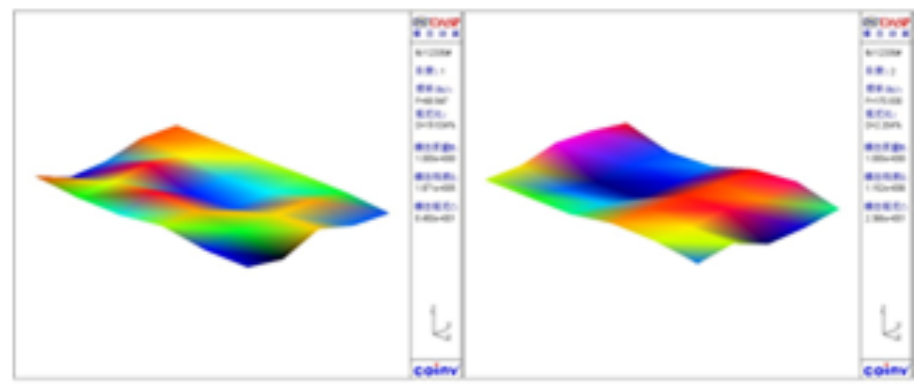

a) 1 order modal

b) 2 order modal

Fig. (8). Sandwich plate modal experiment.

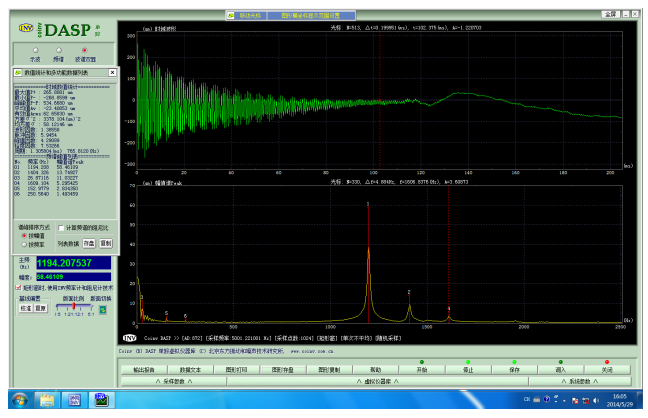

(1) core height is $20 \mathrm{~mm}$

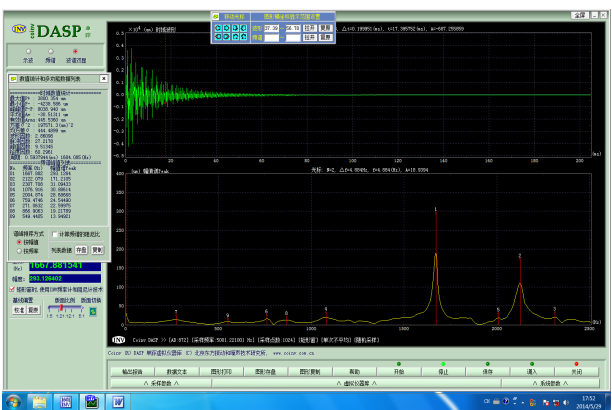

(2) core height is $30 \mathrm{~mm}$

Fig. (9). Frequency response curve of experiment.

Table 3. The natural frequency of different sandwich core height.

\begin{tabular}{|c|c|c|c|}
\hline $\begin{array}{c}\text { Skin Thickness } \\
(\mathbf{m m})\end{array}$ & $\begin{array}{c}\text { Core Height } \\
(\mathbf{m m})\end{array}$ & $\begin{array}{c}\text { Weight } \\
(\mathbf{g})\end{array}$ & $\begin{array}{c}\text { Frequency } \\
(\mathbf{H z})\end{array}$ \\
\hline \hline 1 & 15 & 984 & 1076 \\
\hline 1 & 20 & 1024 & 1194 \\
\hline 1 & 30 & 1052 & 1167 \\
\hline 3 & 15 & 2688 & 865 \\
\hline 3 & 20 & 2706 & 999 \\
\hline 3 & 30 & 2749 & 1263 \\
\hline
\end{tabular}

Mesh side length is $6 \mathrm{~mm}$.

\section{CONCLUSION}

The result shows that the change of core height has a greater impact on the natural frequencies of honeycomb sandwich plates. When the surface thickness of quadrilateral honeycomb sandwich plates becomes thicker, its natural frequency increases with increasing length of core grid. When sandwich mesh length reaches a certain level, the natural frequency increased firstly and then decreased. When the sandwich mesh length is longer enough, the frequency decreased with the increase in the length. When the core height increased, the natural frequency increased. When the quadrilateral mesh becomes longer, its natural frequency appears to decline after the initial increase. The influence of geometric parameters on hexagonal honeycomb sandwich plates is same as on quadrilateral honeycomb and other soft sandwich plates. 
Our experiment verify the results of the study, that is sandwich plate geometric changes at the natural frequency influence honeycomb panels trend; provide reference data for the manufacture and application of sandwich panels.

\section{CONFLICT OF INTEREST}

The authors confirm that this article content has no conflict of interest.

\section{ACKNOWLEDGEMENTS}

This work is supported the Natural Science Foundation of Hebei Province, China (E2012203090). And Qinhuangdao Municipal Science and Technology Research and Development Foundation(2012021A048) and Yan Shan University Dr. Fund (B937) and Young Teachers in Research Fund (A020313). The authors also gratefully acknowledge the helpful comments and suggestions of the reviewers, which have improved the presentation.

\section{REFERENCES}

D. Guojun, H. Yuda, and Z. Xiuli, "Time Domain Characteristic Analysis of Large Amplitude Vibration on Circular Sandwich Plate under Static Load”, Eng. Mech. China, vol. 25, pp. 39-44, April 2008.
[2] L. Xiaoman and D. Guojun, "Nonlinear primary vibration of circular sandwich plates and modal analysis", Adv. Mat. Res., vol. 28, pp. 291-294, 2011

[3] L. Renhuai, "Analysis of plates and shells and Its Application", Engineering, vol. 8, no. 2, pp. 60-67, 2001.

[4] J. Sliseris and K. Rocens, "Optimal design of composite plates with discrete variable stiffness", Compos. Struct., vol. 98, pp. 102-104, 2012

[5] I. Kreja,"A literature review on computational models for laminated and sandwich panels", Cent. Eur. J. Eng., vol. 1, no. 1, pp. 59-80, 2011.

[6] J. W. Hutchinson and Z. Xue,"Metal sandwich plates optimized for pressure impulses", Int. J. Mech. Sci., vol. 47, pp. 545-569, 2005.

[7] X. Qiu, V.S. Deshpande and N.A. Fleck, "Finite element analysis of the dynamic response of clamped sandwich beam subject to shock loading", Eur. J. Mech./Solids A, vol. 22, pp. 801-814, 2005.

[8] A. Vaziri, Z. Xue and J.W. Hutchinson,"Metal sandwich plates with polymeric foam-filled cores", J. Mech. Mater. Solids, vol. 1, pp. 95-128, 2006.

[9] A. Vaziri and J. W. Hutchinson,"Metal sandwich plates subject to intense air shocks", Int. J. Solids Struct., vol. 44, pp. 2021-2035, 2007.

[10] C.S. Manohar and R.A. Ibrahim,"Progress in structural dynamics with stochastic dynamic with stochastic parameter variations", Appl Mech. Rev., vol. 52, pp. 177-96, 1999.

[11] B. Naveenthraj, N.G.R. Iyengar, and D. Yadav, "Response of composite plates with random material properties using FEM and MCS", Adv Compos. Mat., vol. 7, pp. 219-37, 1998.

[12] M.K. Pandit, B.N. Singh, and A.H. Sheikh, "Stochastic perturbation-based finite element for deflection statistics of soft core sandwich plate with random material properties", Int. J. Mech. Sci., vol. 51, pp. 363-371, 2009.

(C) Liu et al.; Licensee Bentham Open.

This is an open access article licensed under the terms of the (https://creativecommons.org/licenses/by/4.0/legalcode), which permits unrestricted, non-commercial use, distribution and reproduction in any medium, provided the work is properly cited. 